\title{
A dimensão subjetiva da queixa de dificuldades de aprendizagem escolar
}

\author{
Telma Silva Santana Lopes ${ }^{1}$, https://orcid.org/0000-0003-3816-4708 \\ Maristela Rossato', https://orcid.org/0000-0001-6457-9005
}

\section{Resumo}

Este artigo objetiva contribuir para a compreensão da complexidade dos processos de ensino e aprendizagem no que se refere à queixa de dificuldades de aprendizagem escolar, entendo-a em sua dimensão subjetiva. A pesquisa foi orientada pela Epistemologia Qualitativa e pela Teoria da Subjetividade de González Rey, ambas apoiadas na abordagem histórico-cultural. As atividades de produção das informações foram realizadas em uma escola pública do Distrito Federal, com duas professoras. Destacamos como contribuição da pesquisa que as configurações subjetivas perpassam processos de produções de sentidos que podem fundamentar concepções de ensino, desenvolvimento e aprendizagem, como também orientam ações e relações pedagógicas.

Palavras-chave: Queixa; subjetividade; aprendizagem.

\section{The subjective dimension of the complaint of school learning difficulties}

\begin{abstract}
This article aims to contribute to the comprehension of the complexity of teaching and learning processes in relation to the complaint of learning difficulties in school, understood in its subjective dimension. The research was guided by the Qualitative Epistemology and the Subjectivity Theory of González Rey, both supported in the historical-cultural approach. The information production activities were carried out in a public school in the Distrito Federal, with two teachers. We emphasize, as a contribution of the research, that the subjective configurations permeate processes of sense production that can base conceptions of teaching, development, and learning, as well as guide actions and pedagogical relationships. Keywords: Complaint; subjectivity; learning.
\end{abstract}

\section{Dimensión subjetiva de la queja de dificultades de aprendizaje escolar}

\section{Resumen}

En este artículo se tiene por objetivo contribuir a la comprensión de la complejidad de los procesos de enseñanza y aprendizaje en lo que se refiere a la queja de dificultades de aprendizaje escolar, la entiendo en su dimensión subjetiva. La investigación fue orientada por la Epistemología Cualitativa y por la Teoría de la Subjetividad de González Rey, ambas apoyadas en el abordaje histórico-cultural. Las actividades de producción de las informaciones fueron realizadas en una escuela pública del Distrito Federal, con dos profesoras. Destacamos, como contribución de la investigación que las configuraciones subjetivas atraviesen procesos de producciones de sentidos que pueden fundamentar concepciones de enseñanza, desarrollo y aprendizaje, como también orientan acciones y relaciones pedagógicas.

Palabras clave: Queja; subjetividad; aprendizaje.

1 Universidade de Brasília - Brasília - DF - Brasil; telsilsanlopes@gmail.com; maristelarossato@gmail.com 


\section{Introdução}

O objetivo da pesquisa foi analisar como as queixas de dificuldades de aprendizagem escolar estão constituídas na subjetividade dos professores, evidenciando desafios e contribuições para reconhecermos a aprendizagem em uma dimensão subjetiva. As discussões propostas no cenário educacional acerca do fracasso escolar e das queixas de dificuldades de aprendizagem geralmente são postas como dificuldades gerais, porém, quando melhor analisadas, verifica-se que grande parte analisa apenas as dificuldades do estudante, sem reconhecer a complexidade das dinâmicas escolares. Tal fato nos indica que essa generalização desconsidera as produções subjetivas geradas em outras zonas da vida dos estudantes, presentificadas no contexto escolar.

Nesse sentido, o problema orientador da pesquisa, ora apresentada, organizou-se em torno da análise da subjetividade do professor, reconhecendo-a como balizadora das ações e relações pedagógicas no contexto escolar. As ações e relações pedagógicas são definidas por Rossato, Souza e Paula (2018, p. 7) como "espaços e tempos dialógicos mobilizados e, ao mesmo tempo, mobilizadores da produção de sentidos subjetivos, numa dinâmica simbólico-emocional, entretecidos pela dinâmica da vida pessoal, acadêmica e profissional do professor". Já as ações e relações aprendentes dizem respeito ao "processo dialógico que ocorre entre professor, estudante e entre pares em espaços e tempos de aprendizagem, perpassados por produções subjetivas do estudante, potencialmente promotoras de desenvolvimento" (Lopes, 2017).

O termo dificuldades de aprendizagem escolar tornou-se mais evidente a partir da universalização do ensino fundamental, revelando fragilidades no processo ensino e aprendizagem. Por outro lado, o fracasso escolar está atrelado ao mau desempenho do sistema educacional do país, frente a avaliações estabelecidas em âmbito nacional e mundial, o que evidencia ausência de investimentos em setores importantes e políticas voltadas para a formação continuada, processos inclusivos e reestruturação física do espaço escolar. Já as queixas escolares dizem respeito à ação do professor, que pode ser motivada por causas diversas, como: indisciplina, baixo rendimento escolar, problemas emocionais, problemas comportamentais, dentre outras.

As produções de Patto (1990), Souza (1996) e Machado (1997) elucidam que as dificuldades de aprendizagem se referem às produções dos atores no cotidiano escolar, colaboram para os altos índices de evasão e repetência escolar revelando uma condição marginal, não só no Brasil, mas também (em) outros países com altos índices de vulnerabilidade social, em relação aos processos de desenvolvimento humano. Verifica-se então, que a escola do século XXI ainda tem muito da escola de séculos passados. Os ideais de uma escola democrática, laica e para todos, ou seja, de um saber universal de qualidade para todos, proposta na Revolução Francesa por Condorcet, constitui-se em um objetivo ainda a ser alcançado por nossa sociedade.
Rossato (2009) sinaliza que impor ao estudante toda a carga de responsabilidades pela sua não aprendizagem pode eximir outros atores implicados no contexto, como também restringir e dificultar uma análise dos demais aspectos que permeiam o contexto escolar, entre eles, os processos relacionais e sentidos subjetivos produzidos por tais atores no processo ensino e aprendizagem. Para refletir sobre as dificuldades de aprendizagem há de se levar em conta o que, de modo geral, se entende por aprendizagem no contexto escolar - aquisição de conhecimentos, representações, comportamentos e domínio de conceitos científicos. Essa compreensão indica como está circunscrito o universo das dificuldades de aprendizagem escolar, demarcando a compreensão que adotamos na presente pesquisa, ou seja, ser reconhecido como um estudante com dificuldades de aprendizagem escolar significa que ele não estaria dentro do esperado pela escola em relação à aquisição de conhecimentos, representações, comportamentos e domínio de conceitos científicos.

\section{A queixa escolar na literatura}

Na revisão da literatura, a análise do material ${ }^{1}$ pesquisado revelou que algumas concepções não sofreram alterações ao longo dos anos, sinalizando que ainda grande parte da responsabilidade pelo fracasso escolar, tendo a queixa escolar como parte do fenômeno, aponta o estudante como produtor ou responsável. Os artigos, de um modo geral, sinalizam caminhos pelos quais a escola e os envolvidos no cenário da queixa precisam se propor a trilhar quando se pensa em dificuldades de aprendizagem e queixas escolares, em razão das poucas mudanças operadas.

Os estudos que relacionam a queixa escolar ao contexto da formação e identidade do psicólogo (Silva, 1988; Castanho, 1996; Souza, 1996; Bastos, 1999; Feijó, 2000), evidenciam a necessidade de formação adequada e tecem reflexões sobre a identidade do psicólogo, cuja formação inicial não perpassa apenas o contexto escolar. A queixa escolar na perspectiva do atendimento e intervenção em clínica, clínicas-escola e a realização de diagnósticos, (Pereira, 1983; Brasil, 1989; Ciasca 1990; Freller, 1993; Mazzolini, 1999; Modelli, 1999; Ribeiro, 2001; Busetti, 2002; Urban, 2003; Avoglia, 2006) é analisada pelo viés interventivo, a partir de aportes teóricos e práticas específicas.

Silva (2013) aborda a criatividade do Pedagogo do Serviço Especializado de Apoio à aprendizagem no DF, no atendimento as queixas escolares. A autora constata que a criatividade do pedagogo ainda é pouco expressa nas diferentes áreas de atuação analisadas, justificadas tanto pelos elementos subjetivos individuais não favoráveis à sua atuação, quanto pela subjetividade social da escola. Pimenta (2012) analisou como a proposta de escolaridade em ciclos no Bloco Inicial de Alfabetização do DF, interferia nas con-

1 Utilizaram-se as Bases de Indexação Pepsico e Scielo. Foram localizados 52 artigos publicados entre os anos 1997 a 2015 com o termo queixa escolar. 
cepções e nas práticas pedagógicas de professores acerca da queixa escolar.

Registramos também que o estudante foi colocado em evidência no estudo de Trautwein (2005). Lima (1991) evidenciou a família e seu papel no fenômeno da queixa escolar. Torezan (1990) e Pacífico (2000) abordaram a questão do docente no processo. Lopes (2013) abordou o processo de medicalização no atendimento a queixa.

Os estudos citados anteriormente colaboraram para evidenciar os avanços no cenário escolar em relação à problemática ao envolver outros atores de maneira mais crítica, discutindo concepções, relações, percursos, ações e processos avaliativos; entretanto, a dimensão subjetiva que está na base das ações e relações pedagógicas não tem sido discutida em relação às queixas de dificuldades de aprendizagem escolar. Nesse sentido, a Teoria da Subjetividade em desenvolvimento por González Rey e diversos colaboradores nos auxilia no sentido de produzir novas zonas de sentido e inteligibilidade no curso de estudos empíricos e construtos teóricos que contemplem uma visão mais sistêmica do indivíduo, onde não cabe estudá-lo isolado do seu meio social.

\section{A subjetividade e as queixas escolares}

Apoiados na abordagem histórico-cultural de Vygotsky e na Teoria da Subjetividade de González Rey, além de pesquisadoras como Mantoan (2003), Raad \& Tunes (2011), Tacca \& Mitjáns Martínez (2011; 2014), Rossato (2009), Rossato \& Mitjáns Martínez (2011), destacamos a importância das relações que permeiam o processo de ensino e aprendizagem entre professor/estudante e entre outros pares no contexto escolar. As contribuições de González Rey (2005a) sobre a subjetividade, definida como "a organização dos processos de sentido e de significação que aparecem e se organizam de diferentes formas" (p. 108), dão um impulso para a compreensão da dinâmica das relações escolares em sua dimensão subjetiva, pois, no processo de ensinar e aprender, são produzidos sentidos subjetivos que podem mobilizar a superação de dificuldades geradas nas ações e relações entre sujeitos.

A abordagem histórico-cultural tem nos estudos de L. S. Vygotsky (1896-1934) e outros Psicólogos russos como L. I. Bozhovich (1908-1981) e B. F. Lomov (1927-1989) referências importantes em se tratando de aprendizagem e de desenvolvimento humano, influenciados pelas leituras de Marx e Engels, que delegavam importante papel ao trabalho e ao homem como um ser social. O modelo interacionista embasado nesses pressupostos aponta para um sujeito que se constitui nas relações sociais, culturais e históricas em um processo recursivo. Esse processo de constituir-se sujeito, aprender e se desenvolver são perpassados pela apropriação da linguagem, pela apropriação de conceitos, pelo papel preponderante do outro e posteriormente pelo trabalho.
Para González Rey (2005a) a subjetividade é uma dimensão inseparável da condição humana, uma produção constituída nas ações e relações da pessoa com o mundo a sua volta. Diz respeito ao que constitui o ser humano em essência, sendo uma produção simbólico-emocional. Organiza-se em termos da subjetividade social e da subjetividade individual, sendo, o sujeito, constituído na tensão dessas duas dimensões. Nas relações humanas gestadas no meio social, a todo o momento, o indivíduo se depara com experiências únicas mobilizadoras de sentidos subjetivos que González Rey (2012) define como unidades simbólico-emocionais - expressões de experiências vividas pelo sujeito em seu percurso de vida. São produções do momento atual, da experiência, são inseparáveis das configurações subjetivas, só podendo ser analisadas nessa forma de organização, pois eles são a sua base constitutiva.

As configurações subjetivas podem ser entendidas como momentos de integração e organização dos sentidos subjetivos produzidos no curso das experiências, podendo ser entendidas como complexos sistemas, organizadores e geradoras dos sentidos subjetivos. Os sentidos subjetivos, em relação às configurações subjetivas são, simultaneamente, produto e processo constitutivo, uma vez que as novas produções subjetivas são processos e formações da ordem do simbólico-emocional já constituídos e que, diante das novas experiências, assumem desdobramentos sempre singulares (González Rey \& Mitjáns Martínez, 2017).

O conceito de subjetividade, bem como seu valor heurístico, ainda é pouco conhecido no espaço escolar, porém permeia de maneira decisiva as ações e relações aí estabelecidas. Ao nos propomos a compreender a queixa escolar no âmbito da constituição subjetiva do professor, é necessário olhar para a sua história, dinâmicas relacionais e para as produções subjetivas que constituem suas ações e relações pedagógicas (Lopes, 2017).

Aprender, especialmente o processo de aquisição da leitura e escrita, é um processo complexo, que envolve também recursos emocionais do professor e do estudante. González Rey (2014) alerta acerca do equívoco da instituição em insistir em um processo despersonalizado, omisso e com um fim em si mesmo, onde não há espaços para erros, reorganizações e valorização de saberes anteriores. Reitera a necessidade de a aprendizagem ser entendida como um processo complexo e subjetivo, o que implica considerar que: "a aprendizagem não é um processo meramente individual, mas também sociorrelacional” (González Rey \& Mitjáns Martínez, 2017, p. 57). Isso elucida muito sobre as dificuldades de aprendizagem, aspecto que nos interessa, pois estão na gênese da queixa escolar.

\section{Metodologia}

A pesquisa foi orientada pela metodologia construtivo-interpretativa, fundamentada na Epistemologia Qualitativa, desenvolvida por González Rey (2005b, 2012, 2014),cujos princípios fundamentais são o caráter constru- 
tivo-interpretativo do conhecimento, a legitimação da contribuição singular que cada caso pode aportar ao conhecimento e o caráter comunicacional e dialógico no curso da pesquisa.

\section{Construção do cenário social da pesquisa}

A construção do cenário social da pesquisa é um momento de mobilização das pessoas para que assumam o espaço de participantes da pesquisa, desejando fazerem parte do processo (Rossato; Martins \& Mitjáns Martínez, 2014). A pesquisa foi desenvolvida em escola pública, envolvendo participantes ${ }^{2}$ dos anos iniciais do Ensino Fundamental.

\section{Procedimentos e instrumentos}

Os instrumentos, no contexto da metodologia construtivo-interpretativa, constituem-se em espaços mobilizadores da expressão do outro. Sua utilização é orientada por tensionamentos dos participantes, levando-os a produzirem reflexões inéditas, com maior potencial de expressão da constituição da subjetividade. Foram utilizados: Complemento de Frases - instrumento criado por González Rey e Mitjáns Martínez (1989), contendo indutores diretos e indiretos; Redação - instrumento aberto que permite ao participante colocar-se livremente sobre o problema, a partir de temas mobilizadores de reflexão; Dinâmicas conversacionais - momentos interativos entre os participantes e a pesquisadora objetivando uma interação e a expressão dos mesmos.

\section{O processo de construção e análise das informações}

A análise aqui apresentada é resultado das informações produzidas com duas professoras, que têm estudantes com queixa formal de dificuldades de aprendizagem. A análise das informações é um processo que ocorre no curso da pesquisa, possibilitando, ao pesquisador, abrir novas frentes de produção de informações em direção ao problema investigado. $O$ processo da pesquisa foi inspirado no modelo construtivo-interpretativo, a saber: produção de indicadores da constituição subjetiva dos participantes, formulados pela tessitura das informações produzidas a partir dos instrumentos utilizados; construção de hipóteses sobre como esses indicadores da constituição subjetiva possibilitam compreender o objeto em análise - queixa de dificuldades de aprendizagem escolar; produção de novos campos de inteligibilidade sobre o problema em estudo. Todo esse processo é permanentemente orientado pela base teórica do pesquisador, indissociando empiria e teoria.

2 Os participantes assinaram Termo de Consentimento Livre e Esclarecido e a pesquisa foi aprovada pelo Comitê de Ética em Pesquisa da área de Ciências Humanas. Todos os nomes são fictícios.

\section{Resultados e Discussão}

O trabalho lento e criterioso do pesquisador se assemelha um pouco aos dos artistas visuais que, por meio da arte, expressam tensões e contradições que reconhecem no mundo real, ao mesmo tempo em que produzem uma realidade, como resultado de suas construções e interpretações. Trabalham ambos interpretando e expressando sentidos subjetivos constitutivos da subjetividade e, mesmo que fluídos e contínuos em suas experiências nos espaços históricos em que atuam, vão imprimindo marcas em sua psique, demarcando que a subjetividade não é um fenômeno individual, particular, mas um fenômeno simultaneamente social e individual.

O desafio posto então, por meio das análises das informações produzidas nos momentos de conversação, observação, redação e complemento de frases foi de construir indicadores coerentes que sinalizassem elementos da subjetividade que poderiam estar relacionados às ações dos professores em relação à queixa de dificuldades de aprendizagem escolar. A família e a profissão docente como configurações subjetivas dominantes na constituição da subjetividade individual foram identificadas em ambos os professores que se colocaram à disposição para participar da pesquisa relativa à queixa escolar, no momento da apresentação da pesquisa ao corpo docente da escola. Entretanto, o que poderia parecer uma semelhança, revelou, no decorrer das análises, a complexidade constitutiva dos atores no universo escolar, chamando a atenção para a dimensão simbólico-emocional da subjetividade individual, expressa nas ações e relações pedagógicas.

\section{Caso 1 - A Professora Fátima}

Fátima tem 46 anos de idade e é professora há 13 anos, sendo nove anos na rede pública de ensino e quatro em escolas privadas. No momento da pesquisa, estava há três anos na escola. Ao analisar a trajetória da professora, foi possível identificar que teve outras oportunidades de trabalho e carreira em sua vida, mas escolheu a profissão de professora, conforme seus relatos, revelando sentir-se realizada com a escolha, como exemplificado a seguir.

Preferi realmente o magistério, a minha mãe já era professora e aquilo de certa forma influencia a gente né?... Aí trabalhei numa escola lá na Asa Norte. Uma escola construtivista e aquilo me fez amar, mais ainda, o magistério né, o caminho do ensino.(Trechos da Dinâmica Conversacional)

Em algumas frases do complemento de frases, identificamos:

Na escola: "um prazer"; Sou um professor: "dedicada"; Amo: "ensinar"; Sempre quis: "educação continuada"; Dedico a maior parte do meu tempo: "no meu trabalho" (Trechos do Complemento de Frases). 
Suas experiências profissionais anteriores foram mobilizadoras para que, na atualidade, ela tivesse grande iniciativa, criatividade e disposição ao novo, agregando e solidificando conhecimentos favorecedores à aprendizagem dos seus estudantes. As experiências positivas vivenciadas pela professora em sua história de vida mobilizaram a produção de sentidos subjetivos que influenciaram a sua escolha profissional e, de certa forma, pautam suas ações e relações ainda nos dias atuais.

A criança não aprende apenas com um exercício, é preciso Ihe disponibilizar o máximo de recursos possíveis. Algumas coisas, às vezes, bloqueiam o conhecimento, de modo que a criança acaba não compreendendo o que falamos. Por isso, a utilização de outros recursos metodológicos favorece o processo de ensino-aprendizagem. (Trecho da Dinâmica Conversacional)

Evidencia-se o compromisso de Fátima com sua prática e formação continuada, tentando pôr em movimento tudo o que aprende nos cursos que faz. As expressões de Fátima nos possibilitam perceber sua consciência do papel social do professor, seu compromisso com as ações e relações pedagógicas. Também evidenciamos uma postura crítica, positiva e construtiva, expressando seus atributos de sujeito nas ações e relações pedagógicas, como podemos perceber, a seguir, ao relatar as dificuldades enfrentadas pela ausência de ações de coordenação pedagógica ${ }^{3}$, recursos e envolvimento por parte de alguns profissionais que atuam com ela na escola.

Por que geralmente, professores se reúnem, conversam mais do que coordenam, entende? (risos) Em vez de estar planejando uma boa aula, com vários recursos... é claro que são poucos, né, mas, o que têm disponível a gente pode utilizar na sala de aula, né?...Tem escolas mais proativas que tem uma coordenação, que orienta, que nos faz reunir, que nos faz debater sobre coisas e como realizar certas coisas e em outras já não acontece isso né? A maioria, é assim, que eu já estive. Eu já estive em várias desde que trabalhei no contrato temporário... Então a escola não caminha no fluxo né, ela fica andando como um rio maluco né, entre as pedras, e assim acontece nas escolas públicas né. No geral é assim... Eu gosto de trabalhar artes por que é mais uma coisa que elas estão manipulando e faz lembrar o conteúdo... Agora, às vezes, faço, invento outras coisas né, para ficar mais ou menos igual (referindo-se às artes). (Trechos da Dinâmica Conversacional)

No cotidiano escolar de Fátima, era no contexto de sua sala de aula que executava, com autonomia, o trabaIho que acreditava importante aos seus estudantes. Isso foi possível constatar, entre outros momentos,quando seus

3 Coordenação Pedagógica, no contexto das escolas públicas do DF, é um espaço-tempo para fins de estudos, formação continuada e preparação de aulas. Corresponde a 11 horas semanais que são remuneradas e completam as 36 horas de trabalho. estudantes referendaram o projeto de leitura, como uma atividade muito envolvente, prazerosa e de que eles gostavam (Oficina Compartilhada). Esse momento foi significativo para confirmar, à própria professora, a importância do trabalho que realizava, evidenciando o interesse e o prazer que essa atividade estava gerando neles. Para a professora, a aprovação e o reconhecimento dos estudantes era mais importante do que a de colegas de trabalho a quem tinha muitas queixas pela falta de envolvimento e compromisso com a formação dos estudantes. "Meninas, vocês querem trabaIhar com isso? 'Não! 'E com isso? 'Não! '...Desse modo, fica difícil, pois quero fazer uma coisa, convido os outros colegas e eles dizem não. Isso é desestimulante" (Trechos da Dinâmica Conversacional).

As análises das informações também indicaram a presença de sentidos subjetivos relacionados a produções subjetivas geradas em sua história familiar - orientada pelo respeito, compreensão e valorização da instituição familiar - se faz presente nas ações e relações pedagógicas com as famílias dos seus estudantes, reconhecendo as dificuldades pelas quais as famílias em situação de vulnerabilidade passam. Em algumas frases do complemento de frases, identificamos:

Lamento: "não ter tido meu pai durante a infância"; Meu maior medo: "perder alguém que amo"; Minha preocupação principal: "com a familia, bem-estar"; Luto: "pela família"; O lar: "Lugar de repouso" (Trechos do Complemento de Frases).

Ao ser indagada sobre a participação das famílias na aprendizagem dos filhos, Fátima destaca:

Isso é muito relativo, a gente não pode dizer que é assim, assado, por que cada família é um universo... Por que as famílias, às vezes, não cumprem o seu dever, não por que não queira... Eu não posso comparar uma criança que tá lá no Plano Piloto e uma criança que está aqui nessa invasão, é diferente. (Trechos da Dinâmica Conversacional)

Fátima carece de apoio, recursos, espaço para o desenvolvimento de projetos específicos e acompanhamento pedagógico. Muitas vezes, ela tenta resolver, como pode, os problemas que vão aparecendo, mas sabe que isso não é suficiente. Numa atividade da pesquisa em que deveria escrever um final para a história de uma professora com um estudante que apresentou dificuldades de aprendizagem durante o ano, Fátima se expressa, como a seguir:

Ela estará consciente de que os resultados não dependerão única e exclusivamente dela, mas de todos, se todos estiverem envolvidos e motivados para a caminhada; realizando dessa forma o percurso proposto. O final de tudo, o construto, será apenas o clímax de algo construído por todos. (Trecho da Redação) 
Reconhecemos aqui a presença de indicadores de sentidos subjetivos relacionados à perspectiva de coletividade e de sensibilidade com o outro que não fica circunscrita à sua família, possibilitando o reconhecimento das condições de vida, as necessidades e os desafios diferenciados que cada família enfrenta. Com o exemplo dessa professora podemos perceber como a constituição da subjetividade dialoga permanentemente entre o social e o individual, sem fronteiras. Ao finalizar sua redação, afirma:

Sabendo que geralmente as histórias se repetem ano após ano, ela descansou o coração convicta de que o ano que se inicia vem com outras perspectivas, outras configurações, outras nuances e, acima de tudo, outros sujeitos. Sendo assim, diante de outro cenário não deixará de acreditar e investir tempo e recursos disponíveis para realizar o que tiver em seu alcance, para que, no decorrer do processo, com sua nova turma, possa ver o que existe de mais importante na interação entre eles: a caminhada. (Trecho da Redação)

O compromisso com sua prática e formação continuada, o compromisso com suas ações e relações pedagógicas, sua iniciativa, criatividade e disposição para o novo, a consciência de seu papel social, sua postura crítica, positiva e construtiva são indicadores da existência de sentidos subjetivos que convergem na compreensão de como a profissão docente está configurada subjetivamente em Fátima. Da mesma forma, o discernimento e a consciência quanto às dificuldades enfrentadas pelos estudantes, e respectivos familiares, e a perspectiva de coletividade e de sensibilidade com o outro são indicadores da existência de sentidos subjetivos que convergem na compreensão de como a família está configurada subjetivamente em Fátima. Os sentidos subjetivos nunca podem ser nominados, mas, apenas, realizadas aproximações que possibilitam ao pesquisador construir indicadores da existência dos mesmos (González Rey \& Mitjáns Martínez, 2017).

Uma configuração subjetiva constitui-se pela história de produções de sentidos subjetivos mobilizados nas ações e relações vividas em diferentes zonas da vida. Fátima, ao fazer referência às experiências anteriores e questionar a dinâmica pedagógica da escola atual, está se movimentando em sua história de produção de sentidos subjetivos. "Passado, presente e futuro organizam-se como uma unidade no movimento das configurações subjetivas, o que faz que a temporalidade, como dimensão de sentido subjetivo, tenha um caráter fortemente imaginário em nossas vidas" (González Rey \& Mitjáns Martínez, 2017, p. 63). A profissão docente, como configuração subjetiva, por exemplo, ao mesmo tempo em que tonaliza os novos sentidos subjetivos que são produzidos no cotidiano escolar, é tonalizada pelas novas produções, relacionadas a outras configurações subjetivas, num movimento circular aberto, pois sempre podem surgir novos sentidos subjetivos que promovam uma reconfiguração na constituição subjetiva atual.

Os indicadores dos sentidos subjetivos que estão relacionados à profissão docente e à família nos levaram a considerar a hipótese de que, para Fátima, o problema da queixa de dificuldades de aprendizagem escolar não é responsabilidade de um único envolvido. A professora Fátima não apontou a responsabilidade unilateral do estudante, da família ou da escola. Ao contrário, para ela, a responsabilidade é conjunta, onde cada um deve mobilizar-se para a aprendizagem e o desenvolvimento do estudante. Para isso, investe em sua formação, procurando com os recursos que desenvolve, intervir realizando um trabalho pedagógico de qualidade.

\section{Caso 2 - A professora Maria}

A professora Maria tem 48 anos de idade, é casada e mãe de dois filhos. Veio do Nordeste para Brasília, onde foi aprovada em um concurso para professora, após trabalhar oito anos em escolas particulares. Trabalha há quatro anos como professora efetiva na SEE/DF e acumula 24 anos no exercício da profissão. Optou pela carreira de magistério em virtude da influência de duas professoras de quem foi aluna ainda criança. Declara-se apaixonada pela profissão e não pensa em realizar outra atividade. Em sala, segue rotinas fixas, as quais se constituem de orações religiosas, organização por filas, saudações à hora da entrada, da saída e dos lanches. Mantém sempre o domínio da turma e uma organização no ambiente da sala de aula.

Maria nos dá pistas interessantes sobre como as memórias afetivas podem ser balizadoras das ações e relações pedagógicas desenvolvidas na escola.

É assim, na $3^{\text {a }}$ série eu conheci duas professoras Tia llma e Maria, tinha 9 anos, hoje eu tenho 48 e não esqueço o nome delas. E eu achava elas lindas, o jeito que elas andavam na sala de aula e eu estudava naquela época numa escola tradicional, uma mesa atrás da outra. E elas andavam no corredor, para lá, para cá e eu ficava olhando para elas e elas me encantavam com o jeito delas, né...Tudo que eu faço com meus alunos eu faço com muito amor, com muito carinho, até a bronca que eu dou neles é com muito amor, com muito carinho. Se eu deixo eles sem intervalo, é com muito amor, muito carinho... E então, daquele ano em diante eu resolvi que eu ia ser professora [fazendo referência às professoras da $3^{a}$ série]... Eu me pego fazendo coisas que elas faziam com a gente até hoje. (Trechos da Dinâmica Conversacional)

O imaginário idealizado sobre um modo de atuação docente, orientado pelas emoções produzidas em sua infância, na relação com suas antigas professoras, é identificado como balizador de suas ações e relações pedagógicas, no tempo presente. As expressões da professora Maria nos revelam um pouco sobre como a constituição subjetiva é forjada nas relações que estabelecemos no curso da vida, onde o ser humano, muitas vezes, não conhece o alcance que tem sua forma de ser e as ações que pratica. Em algumas frases do complemento de frases, identificamos: 
Na escola: "procuro fazer o melhor"; Sou um professor: "dedicado"; Ensinar ganha sentido quando: "aprendo também"; Não esqueço da aula quando: "Lembro da minha professora da $3^{a}$ série"; A sala de aula: "Lugar mágico"; A escola: "Lugar de superações" (Trechos do Complemento de Frases).

A partir dos exemplos vivenciados na infância, ela pauta suas ações e relações idealizadas com os estudantes. No entanto, apesar de sua fala contundente quanto à escolha profissional, o quanto ela ama ser professora e sua disposição em procurar fazer o melhor, ao atribuir magia a sala de aula, Maria a caracteriza como um local próspero, que modifica os que aí adentram, mas, ao mesmo tempo, caracteriza a escola como lugar de superações, sinalizando que as conquistas dependem também de esforços pessoais. O seu esforço pessoal em ser uma boa professora está atravessado por produções subjetivas de natureza diversas, vinculadas ao idealizado e ao real.

No caso de Maria, as memórias afetivas e o imaginário idealizado de docência e de estudante são indicadores da existência de sentidos subjetivos que convergem na compreensão de como a profissão docente está configurada subjetivamente em Fátima. "A experiência vivida só poderá ser conhecida através de suas consequências e efeitos subjetivos colaterais que acontecem na configuração subjetiva da experiência e não pela experiência em si" (González Rey, 2012, p. 28). Não é a experiência que assume preponderância, mas os sentidos subjetivos advindos dela.

Em relação à família, Maria expressa o lugar que ela ocupa em sua vida.

Não posso: "decepcionar meus filhos"; Minha preocupação principal: "Futuro dos meus filhos"; Amo: "Minha família"; Diariamente me esforço: "Para ser uma boa mãe"; Minhas aspirações: "Meus filhos"; Meu maior prazer: "Cuidar dos meus filhos"; Os filhos: "realização de um sonho" (Trechos do Complemento de Frases).

As expressões, a seguir, demarcam como Maria se movimenta entre sua família e a família de seus estudantes:

Eu sempre fui muito bem acompanhada pelos meus pais na escola... Ela[a criança] tem que ter uma família estruturada, ou que não seja estruturada, mas ela tem que ter pais. Quando falo pai, não pai e mãe, pessoas que se interessem por essa criança, que queira o melhor para ela e que não pense que a escola é onde ela vai se educar. A escola é uma extensão da família. É uma extensão da casa. (Trechos da Dinâmica Conversacional)

Família é um elemento orientador da subjetividade de Maria e sua expectativa é de o modo como sua família a acompanhou na escola, quando criança, seja também seguido pelas famílias de seus estudantes. Ao abordar as famílias dos estudantes, delimita fronteiras claras com a escola que não devem ser transpostas.
Papel da escola eu acho que é sinceramente dar o conteúdo e fortalecer os princípios que vem de casa. O papel da familia é trabalhar, é ensinar os princípios pra que esta criança esteja preparada pra poder aprender o conteúdo que a escola tem para passar pra ele.(Trechos da Dinâmica Conversacional)

Suas expressões sobre a família dos estudantes é, de certa forma, contraditória, pois ao mesmo tempo em que fala da continuidade entre as duas instituições - escola como extensão da família, da casa -,demarca claramente que possuem papéis bem distintos. O pressuposto das condições ideais para a aprendizagem ronda o valor simbólico da escola para Maria, limitando suas possibilidades de reconhecer qualidades e possibilidades no contexto devida dos estudantes, entre as diferentes zonas de experiências que são vivenciadas cotidianamente pelos mesmos.

Os sentidos subjetivos produzidos em sua vida escolar na infância a mobilizaram para uma profissão: ser uma professora de uma escola como vivenciada em infância. Porém, no momento, a sua profissão e a escola apresentam outras demandas e Maria demonstra insegurança para enfrentar situações diferentes de seu modelo idealizado de escola e de família. Conhecer as famílias e envolver-se com os estudantes são elementos reconhecidos como desfavoráveis à sua atuação docente.

Eu costumo não perguntar muito, para não me envolver intimamente com a vida da criança, com a família da criança. Eu me conheço e me coloco no lugar dessas crianças. Também não posso me esquecer de que, nesse momento, eu sou uma profissional. (Trechos da Dinâmica Conversacional)

O pressuposto das condições ideais para a aprendizagem a serem desenvolvidas pelas famílias e a insegurança para enfrentar situações diferentes do seu modelo idealizado são indicadores da existência de sentidos subjetivos que convergem na compreensão de como a família está configurada subjetivamente em Fátima. González Rey \& Mitjáns Martínez (2017) reitera que a aprendizagem deve ser entendida como um processo complexo e subjetivo, o que implica considerar que "a aprendizagem não é um processo meramente individual, mas também sociorrelacional” (p. 57). Conceber a aprendizagem como um processo sociorrelacional pressupõe analisar as ações e relações pedagógicas e aprendentes gestadas no contexto escolar.

Postas algumas considerações sobre como a profissão docente e família estão configuradas subjetivamente para Maria, produzimos a hipótese de que a queixa escolar segue na extensão do modelo idealizado de estudante, de funcionamento escolar e de modelo familiar.

Nós estamos abandonados à própria sorte. Quando o aluno, quando a turma se destaca, ela faz parte da escola, quando a turma não se destacou ela é da professora. Eu já tive aqui particularmente, alunos que já foram meus, enquanto eram 
da escola, que eu tive que bater o pé e falar: Eu não vou me responsabilizar sozinha. Ele não é só meu! Ele é nosso...

Tem momentos que a gente se sente como filho sem mãe. (Trechos da Dinâmica Conversacional)

As reflexões produzidas no caso de Maria nos levaram a considerar a hipótese de que o modo como a profissão docente e família estão configurados subjetivamente compromete o reconhecimento da aprendizagem e a educação em sua dimensão subjetiva. Dessa forma, problemas como a queixa das dificuldades de aprendizagem escolar são compreendidos apenas do ponto de vista da necessidade de uma intervenção prática e operacional da escola.

\section{Considerações Finais}

Analisar a constituição subjetiva do professor é um caminho que possibilita compreender alguns fenômenos escolares para além de sua dimensão social. A escola é constituída por pessoas dotadas de uma constituição subjetiva única que dialoga permanentemente com a subjetividade social da escola, sejam os professores, sejam os estudantes, sejam as famílias.

Os processos e formações subjetivos produzidos na trajetória cultural-histórica de cada indivíduo permeiam as ações e relações pedagógicas e aprendentes, desafiando os atores escolares a reconhecerem os fenômenos para além da dimensão cognitiva do estudante e operacional da escola. Os dois casos analisados, mais do que conhecer parte da singularidade constitutiva do professor, possibilitaram avançar na compreensão da complexidade envolvida na produção da queixa de dificuldades de aprendizagem escolar.

Quanto às professoras, identificamos que o fato de estarmos diante de uma profissional realizada e comprometida, como revela a professora Fátima, que reconhece que problemas de aprendizagem não têm estudantes e famílias como responsáveis, ao contrário, é um problema cuja solução perpassa questões estruturais, organizativas e de formação, não a exime de, em muitos momentos, de sentir-se angustiada e desamparada. Mesmo em face de tantos problemas, segue buscando uma prática que favoreça a superação das dificuldades, reconhecendo que, em um universo conturbado, reconhecer e considerar seus estudantes como sujeitos únicos de uma história, é um elemento importante para o desenvolvimento dos mesmos.

Por outro lado, temos a professora Maria que mesmo tendo escolhido a profissão e dizer sentir-se realizada, expressa dificuldades com a escola atual, no tempo presente, tendo dificuldades em reconfigurar subjetivamente os modelos de docência que orientaram sua constituição subjetiva na infância.

À constituição docente perpassam processos de produções de sentidos subjetivos que podem compor concepções de ensino, desenvolvimento e aprendizagem, como também modulam as ações e relações pedagógicas. Nesse sentido, a subjetividade é uma dimensão que precisa ser considerada nos cursos de formação de professores, para que esses sejam espaços de reconfiguração simbólico-emocional dos fenômenos que perpassam a dinâmica escolar, podendo colaborar para o enfrentamento de problemas nesse contexto.

Destacamos, por fim, que nos casos analisados, identificamos família e profissão docente como configuração subjetiva, no entanto, poderíamos ter nos deparado com outras constituições subjetivas nos dois casos analisados, sem que isso fosse impeditivo da análise, uma vez que o ponto central foi chamar a atenção para como a dimensão subjetiva perpassa a atuação docente no contexto escolar. Com este estudo abrimos novas possibilidades de inteligibilidade na compreensão de como as queixas de dificuldades de aprendizagem escolares podem integrar a constituição da subjetividade do professor, considerando a complexidade envolvida nos processos de ensino e aprendizagem.

\section{Referências}

Avoglia, H. R. C. (2006). Avaliação psicológica: a perspectiva sóciofamiliar nas estratégias complementares à prática clínica infantil. Tese de Doutorado, Universidade de São Paulo, Instituto de Psicologia, São Paulo.

Bastos, H. P. (1999). O psicólogo da saúde pública numa proposta de trabalho interinstitucional: a queixa escolar como elo de ligação. Dissertação de mestrado, Instituto de Psicologia, Universidade de São Paulo, São Paulo.

Brasil, A. M. R. C. (1989). Fracasso escolar, uma questão simbólica: estudo analítico junguiano dos dinamismos na família, na escola e na cultura. Dissertação de Mestrado, Instituto de Psicologia, Universidade de São Paulo, São Paulo.

Busetti, L. Z. (2002). Da dificuldade de aprendizagem a psicoterapia. Dissertação de Mestrado, Faculdade de Psicologia, Pontifícia Universidade Católica do Rio Grande do Sul, Porto Alegre.

Castanho, M. I. S. (1996). Da educação para a saúde: o processo de construção da identidade do psicólogo. Tese de Doutorado, Instituto de Psicologia, Universidade de São Paulo, São Paulo.

Chiodi, C. S. (2012). O processo de avaliação psicológica na perspectiva da psicologia histórico-cultural e suas contribuições para o processo de ensino-aprendizagem. Dissertação de Mestrado, Universidade Estadual de Maringá, Maringá.

Ciasca, S. M. (1990). Diagnóstico dos distúrbios de aprendizagem em crianças: análise de uma prática interdisciplinar. Dissertação de Mestrado, Instituto de Psicologia, Universidade de São Paulo, São Paulo.

Feijó, I. S. C. (2000). O discurso de psicólogos escolares sobre sua prática: continuidade e ruptura. Dissertação de Mestrado, Instituto de Psicologia, Universidade de São Paulo, São Paulo. 
Freller, C. C. (1993). Crianças portadoras de queixa escolar: um enfoque winnicottiano. Dissertação de Mestrado, Instituto de Psicologia. Universidade de São Paulo, São Paulo.

González Rey, F. (2005a). Sujeito e subjetividade: uma aproximação histórico-cultural (R. S.L.Guzzo, Trad.). São Paulo: Editora Pioneira Thomson Learning.

González Rey, F. (2005b). Pesquisa Qualitativa e subjetividadeos processos de construção das informações. São Paulo, Ed. Thomson.

González Rey, F. (2012). A configuração subjetiva dos processos psíquicos: avançando na compreensão da aprendizagem como produção subjetiva. In: Mitjánz, M. A.; Scoz, B. J. L.; Castanho, M. I. S. (Orgs.),Ensino e aprendizagem: a subjetividade em foco. (pp. 21-41). Brasília, Liber Livros.

González Rey, F. (2014) O Sujeito que Aprende: desafios do desenvolvimento do tema da aprendizagem na psicologia e na prática pedagógica. In: Tacca, M. C. (Org.), Aprendizagem e trabalho pedagógico. (pp.29-44). Campinas, SP: Editora Alínea.

González Rey, F.; Mitjáns Martínez, A. (1989). La personalidade su educación y desarrollo. Cuidad de La Habana, Cuba: Pueblo y Educación.

González Rey, F.; Mitjáns Martinez, A. (2017). Subjetividade: teoria, epistemologia e método. Campinas, Alínea.

Lima, C. M. B. (1991). A aliança familiar na adaptação escolar ineficaz. Dissertação de mestrado, Instituto de Psicologia, Universidade de São Paulo, São Paulo.

Lopes, L. F. (2013). Medicalização de crianças com queixa escolar e o núcleo de apoio à saúde da família (NASF): uma análise crítica. Dissertação de Mestrado, Instituto de Psicologia, Universidade de São Paulo.

Lopes. T. S. S. (2017). A dimensão subjetiva da queixa de dificuldades de aprendizagem escolar. Dissertação de Mestrado, Instituto de Psicologia, Universidade de Brasília, Brasília-DF.

Machado, A. M. (1997). Avaliação e fracasso: a produção coletiva da queixa escolar. In: Aquino, J. G. (Org.), Erro e fracasso na escola: alternativas teóricas e práticas. (pp. 73-90). São Paulo: Summus.

Mantoan, M. T. E. (2003). Inclusão Escolar: O que é? Por quê? Como fazer? São Paulo: Moderna.

Mazzolini, B. P. M. (1999). O manejo clínico do problema de aprendizagem na perspectiva dos fenômenos transicionais. Dissertação de Mestrado, Instituto de Psicologia, Universidade de São Paulo, São Paulo.

Modelli, A. (1999). Um estudo psicanalítico sobre a escuta dos pais no diagnóstico da dificuldade escolar. Dissertação de Mestrado,
Instituto de Psicologia, Universidade de São Paulo, São Paulo.

Pacífico, J. M. (2000). A queixa docente. Dissertação de mestrado, Instituto de Psicologia. Universidade de São Paulo, São Paulo.

Patto, M. H. (1990). A produção do fracasso escolar: histórias de submissão e rebeldia. São Paulo: T. A. Queiroz.

Pereira, M. S. (1983). Diagnóstico psicológico em clínica escola: um questionamento profissional. Dissertação de Mestrado, Universidade Metodista de São Paulo, São Bernardo do Campo, São Paulo.

Pimenta, M. A. A. (2012). Bloco Inicial de Alfabetização (BIA) e queixa escolar: estudo de caso de uma escola pública do Distrito Federal. Dissertação de Mestrado, Universidade Católica de Brasília, Brasília, DF.

Raad, I.; Tunes, E. (2011) Deficiência como latrogênese. In: Tacca, M. C.; Mitjáns M. A. (Orgs.), Possibilidades de Aprendizagem: ações pedagógicas para alunos com dificuldades e deficiência. (pp. 1545). Campinas, SP: Editora Alínea.

Ribeiro, M. P. O. (2001). Funcionamento cognitivo de criança com queixas de aprendizagem: jogando e aprendendo a jogar. Tese de Doutorado, Instituto de Psicologia, Universidade de São Paulo, São Paulo.

Rossato, M. (2009). O movimento da subjetividade no processo de superação das dificuldades de aprendizagem escolar. Tese de Doutorado. Faculdade de Educação, Universidade Nacional de Brasília-Df.

Rossato, M.; Martins, L. R. R; Mitjáns Martínez, A. (2014) A construção do cenário social da pesquisa no contexto da Epistemologia Qualitativa. In. Mitjáns Martínez, A.; Neubern, M. Mori, V. D. (orgs). Subjetividade contemporânea: discussões epistemológicas e metodológicas. (pp. 35-60). Campinas, SP: Editora Alínea.

Rossato, M.; Mitjáns Martínez, A. (2011). A superação das dificuldades de aprendizagem e as mudanças na subjetividade. In: Tacca, M. C.; Mitjáns M. A. (Orgs.), Possibilidades de Aprendizagem: ações pedagógicas para alunos com dificuldades e deficiência. (pp. 71107). Campinas, SP: Editora Alínea.

Rossato, M.; Souza. J. F. M.; Paula. R. M. (2018). A subjetividade do professor e sua expressão nas ações e relações pedagógicas. Educação em Revista.34.

Silva, R. C. (1988). Trabalho do psicólogo em centros de saúde: algumas reflexões sobre as funções da psicologia na atenção primária à saúde. Tese de doutorado, Instituto de Psicologia, Universidade de São Paulo, São Paulo.

Silva, F. B. M. R. (2013). A criatividade do pedagogo diante das queixas escolares. Dissertação de mestrado, Faculdade de Educação, Universidade de Brasília, Brasília. 
Souza, M. P. R. (1996). A queixa escolar e a formação do psicólogo. Tese de doutorado, Instituto de Psicologia, Universidade de São Paulo, São Paulo.

Tacca, M. C.; Mitjáns M. A. (Orgs.). (2011). Possibilidades de Aprendizagem: ações pedagógicas para alunos com dificuldades e deficiência. Campinas, SP: Editora Alínea.

Tacca, M. C. (Org.). (2014). Aprendizagem e trabalho pedagógico. Campinas, SP: Editora Alínea.
Torezan, A. M. (1990). Problemas de ensino e papéis do professor: uma análise das falas de professores em reuniões de discussão. Tese de doutorado, Instituto de Psicologia, Universidade de São Paulo, São Paulo.

Trautwein, C. T. G. (2005). O sentido atribuído à queixa escolar por quem não se queixa - o aluno. Dissertação de mestrado, Universidade São Marcos, São Paulo.

Urban, M. L. (2003). O Método Ramain: do tratamento da dificuldade escolar à evolução pessoal. Tese de doutorado, Instituto de Psicologia, Universidade de São Paulo.

Recebido em: 13 de junho de 2017

Aceito em: 11 de janeiro de 2018 unrestricted use, distribution and reproduction in any medium, provided the original article is properly cited. 